\title{
Tailor-Made Nanostructured Ion Selective MCM-48 Membranes
}

Sankhanilay Roy Chowdhury, Riaan Schmuhl, Klaas Keizer, Albert van den Berg, Johan E. ten Elshof and Dave H.A. Blank

$\mathrm{MESA}^{+}$Research Institute, University of Twente

P.O. Box 217, 7500AE, Enschede, The Netherlands

\section{ABSTRACT}

Mesoporous templated MCM-48 silica was prepared using a $\mathrm{C}_{16}$ surfactant as template. The MCM-48 powders and thin films were characterized by different techniques. Two types of porous supports were used, namely macroporous $\alpha$-alumina and silicon microsieves. The supported MCM-48 layers were applied as liquid permeable membranes in pressure-driven nanofiltration and electric field-mediated ion transport experiments.

\section{INTRODUCTION}

A disadvantage of conventional mesoporous inorganic membranes such as $\gamma$-alumina is their wide pore size distribution and the high tortuosity of the separating layer, which affects the intrinsic separation selectivity and permeability negatively. These disadvantages may be solved by employing template-directed synthesis methods for the formation of the mesoporous layer. A well-known example of a templated inorganic material is mesostructured silica. Templated silica can be synthesized using arrays of self-assembled surfactant molecules as structure directing templates, around which the inorganic precursor species are polymerized [1]. Depending upon surfactant concentration and processing conditions, the final pore structure of silica will exhibit hexagonal, cubic (MCM-48) or lamellar symmetry [1,2]. In view of their high porosity and wellordered pore geometries with narrow pore size distributions and low tortuosity, thin films of templated mesoporous materials are potential candidates for membrane applications. Although thin film formation on dense substrates has received considerable attention lately [3,4], only few works on film formation on porous supports have been reported to date [5]. MCM-48 has an interconnected 3D channel system [6], so that a low tortuosity in all directions is expected. This feature should lead to a high liquid permeability of the layer. The small pore sizes and narrow pore size distributions allow complete double layer overlap inside the membrane pores, which can give rise to high selectivity in ion-separation processes. Two types of applications will be demonstrated here. The first is nanofiltration (NF), where ion size and charge, as well as membrane surface charge and double layer thickness determine the level of separation [7]. Here the electrical double layer overlap inside the membrane pores will prevent charged solute transport through the membrane under application of an external mechanical pressure field. The second type of application involves the use of an externally tuneable electrical field over the membrane, so that active control over the transport of specific ionic species can be achieved. This development may lead to new intelligent interconnects between fluid channels in microchemical systems (MiCS) and micro-total analysis systems ( $\mu \mathrm{TAS}$ ) [8]. The transport of cationic species through MCM-48 membranes mediated by a variable external electric field can be regarded as a model system for some of these applications $[9,10]$. Control over the transport rate of species is obtained by the electric field $[10,11]$, while anion or cation selectivity is achieved 
by the complete overlap of a negatively or positively charged diffuse double-layer inside the pores, depending on the total ionic strength [10] and $\mathrm{pH}$.

In this study it is demonstrated how mesoporous MCM-48 silica layers on different porous supports can be used in these two types of membrane processes.

\section{EXPERIMENTAL DETAILS}

\section{Preparation of supported surfactant templated mesoporous silica membranes}

The $\alpha$-alumina supports ( $2 \mathrm{~mm}$ thick, $39 \mathrm{~mm}$ diameter, pore size $\sim 100 \mathrm{~nm}$, porosity $30 \%$ ) were made by colloidal filtration of well-dispersed $0.4 \mu \mathrm{m} \alpha$-alumina particles [12]. Silicon microsieves ${ }^{\circledR}(1 \mu \mathrm{m}$ thick, $0.5 \mathrm{~cm}$ diameter with circular-shaped perforations of $0.5 \mu \mathrm{m}$ diameter, overall porosity $\sim 30 \%$ ) were supplied by Aquamarijn (The Netherlands).

Surfactant-templated silica sols were synthesized using the cationic surfactant cetyltrimethyl-ammonium bromide (CTAB, Aldrich) and tetraethoxy-orthosilicate (TEOS, Aldrich) derived sols as described elsewhere [13]. Spin-coating and dip-coating techniques were used to deposit thin silica films on silicon wafers (004 type) and $\alpha$-alumina supports, respectively. After coating the layers were dried at room temperature and subsequently heated to $400^{\circ} \mathrm{C}$ in air for 2 $\mathrm{h}$ to calcine the silica film (thickness $\sim 200 \mathrm{~nm}$ ) and remove any residual organics.

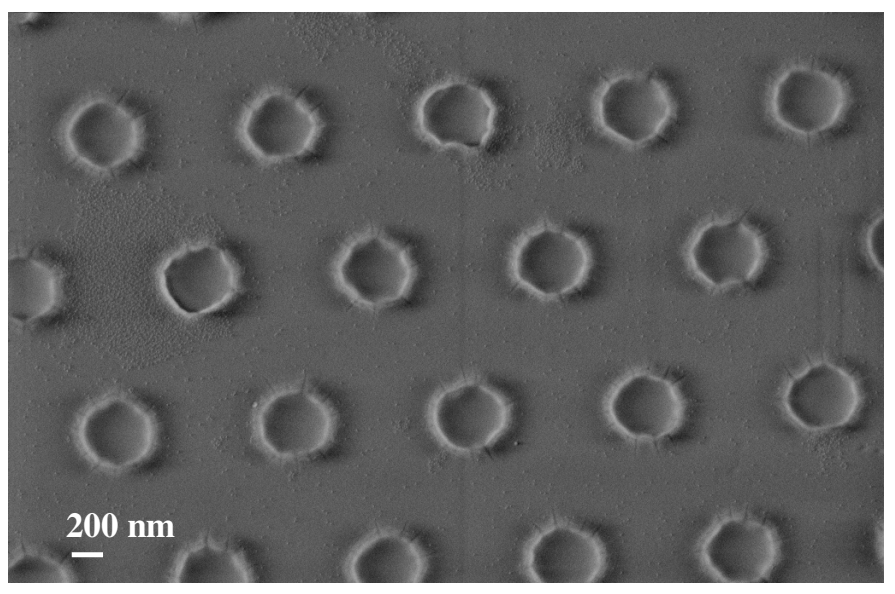

Figure 1. SEM photo of a MCM 48 coated silicon microsieve

The MCM-48 films were checked under SEM for the absence of defects, see figure 1. X-ray diffraction (XRD) patterns of supported silica layers were recorded using a Philips SR5056 with $\mathrm{Cu} \mathrm{K} \alpha$ radiation. BET measurements (Micromiretics) were performed at $77 \mathrm{~K}$ on dried and calcined silica powders with $\mathrm{N}_{2}$ as the condensable gas.

\section{$\underline{\text { Nanofiltration experiments }}$}

The steady state water fluxes through a $\alpha$-alumina supported MCM-48 membrane, a $\alpha$ alumina support and a conventional $\alpha$-alumina supported $\gamma$-alumina membrane were measured. NF measurements were performed with the water-soluble amino acid phenylalanine (Aldrich) as 
a model solute at a concentration of $0.6 \mathrm{mM}$. Retention studies were carried out in a dead end NF cell [14]. The volume of the cell is $1 \mathrm{dm}^{3}$ and the operating pressure was kept in the range of 1-7 bar. The stirring speed in the cell was kept constant at $200 \mathrm{rpm}$. The retention of a membrane is expressed by the retention coefficient which is defined by $R_{o b s}=1-C_{p} / C_{b}$, with $C_{p}$ the solute concentration in the permeate solution and $\mathrm{C}_{\mathrm{b}}$ the solute concentration in the feed solution. The concentration of the amino acid was measured with UV-vis spectrometry at $213 \mathrm{~nm}$ (Pharmacia Biotech, Ultraspec 3000 UV/ Visible Spectrophotometer).

\section{Field mediated transport experiments}

The experimental set-up is shown in figure 2. The membrane (surface area $0.038 \mathrm{~cm}^{2}$ ) was placed between the two halves of a U-shaped tube. The $\mathrm{pH}$ was regulated with $\mathrm{NaOH}$ or $\mathrm{HNO}_{3}$ solutions. The $\mathrm{Cu}^{2+}$ ion concentration was analysed by atomic absorption spectroscopy. A dc potential difference $\Delta V$ was imposed [10] between Pt electrodes using a potentiostat. $\Delta V$ is defined as $\Delta V=V_{\mathrm{B}}-V_{\mathrm{A}}$, with $V_{\mathrm{A}}$ and $V_{\mathrm{B}}$ the electrode potentials at the $\mathrm{A}$ and $\mathrm{B}$ side, respectively. The ion fluxes were calculated from the concentration changes with time after reaching steady state conditions. Prior to the experiment the membranes were left for $12 \mathrm{~h}$ in the buffer solution to ensure complete wetting.

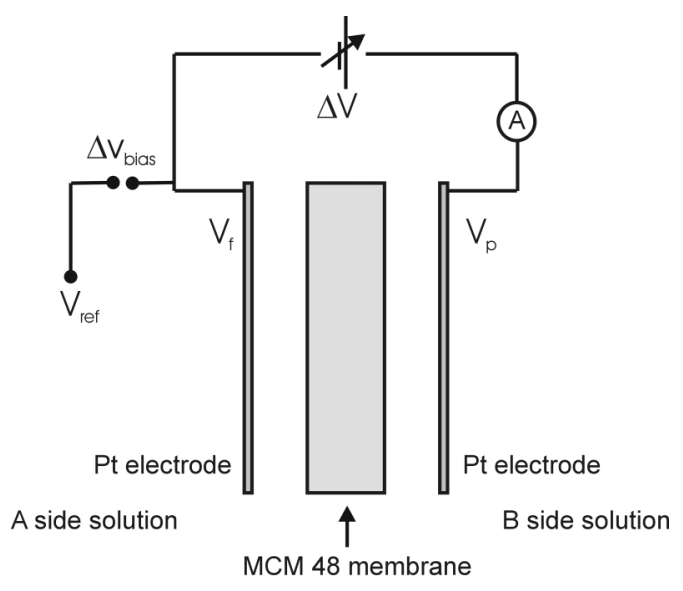

Figure 2. Schematic diagram of the experimental set-up.

\section{RESULTS AND DISCUSSION}

\section{Characterization of the templated silica membrane}

Figure 3 shows a small angle XRD pattern of $200 \mathrm{~nm}$ thick uncalcined and calcined silica films after deposition on a dense silicon wafer. The X-ray pattern matches the pattern of an ordered mesoporous MCM-48 phase with unit cell $a \sim 9.2 \mathrm{~nm}$. The marked sharp peaks are probably from crystalline $\mathrm{CTAB}$ and they disappear upon calcination. The sample retains its mesostructure after calcination but with smaller $d$-spacing (figure 3, $a \sim 6.3 \mathrm{~nm}$ ). We did not observe diffraction at low angles in the films that had been deposited on porous $\alpha$-alumina supports. This is probably due to the roughness and texture of the alumina support, which 
promotes local nucleation and growth of ordered domains with different orientations at length scales that are too small to be detectable by XRD. Permporometry experiments [12] with cyclohexane on the alumina-supported MCM-48 membrane indicated that the calcined silica films are porous, defect-free and have a Kelvin radius $<1.7 \mathrm{~nm}$. This is in agreement with nitrogen sorption data on unsupported MCM-48 powder, from which an average pore diameter of 2.8-3.4 nm was calculated.

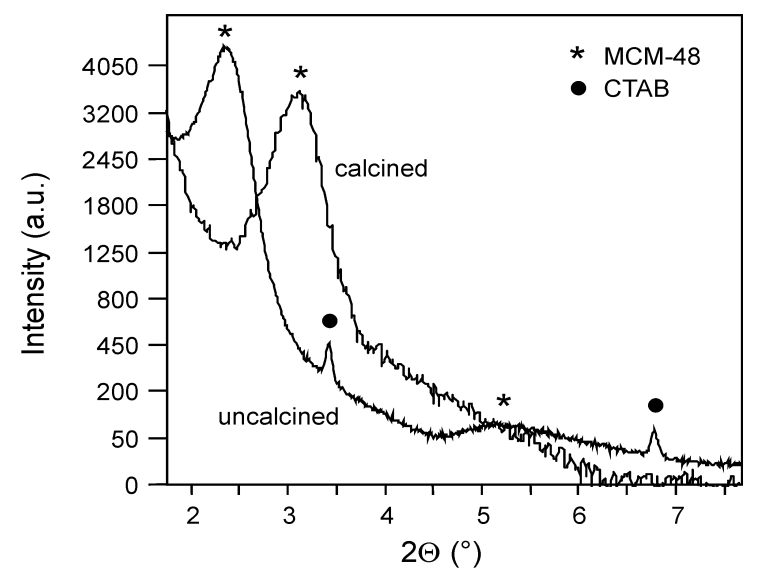

Figure 3. XRD diagrams of uncalcined air-dried and calcined silica layer on silicon (004) wafer.

\section{$\underline{\text { Nanofiltration experiments }}$}

The steady state water flux through the supported mesoporous silica membrane is shown in figure 4 . The water flux increased with increasing pressure. The permeability of water through supported MCM-48 was lower than that of the macroporous $\alpha$-alumina support, but larger than the conventional supported $\gamma$-alumina membrane. Since the $\gamma$-alumina layer is $\sim 1 \mu \mathrm{m}$ thick, has a pore size of 4-6.5 nm and a total porosity of $\sim 50 \%$, the higher permeability of the MCM-48 membrane can be explained by its lower tortuosity, smaller layer thickness $(\sim 65-70 \mathrm{~nm})$ and higher porosity $(\sim 60 \%)$.

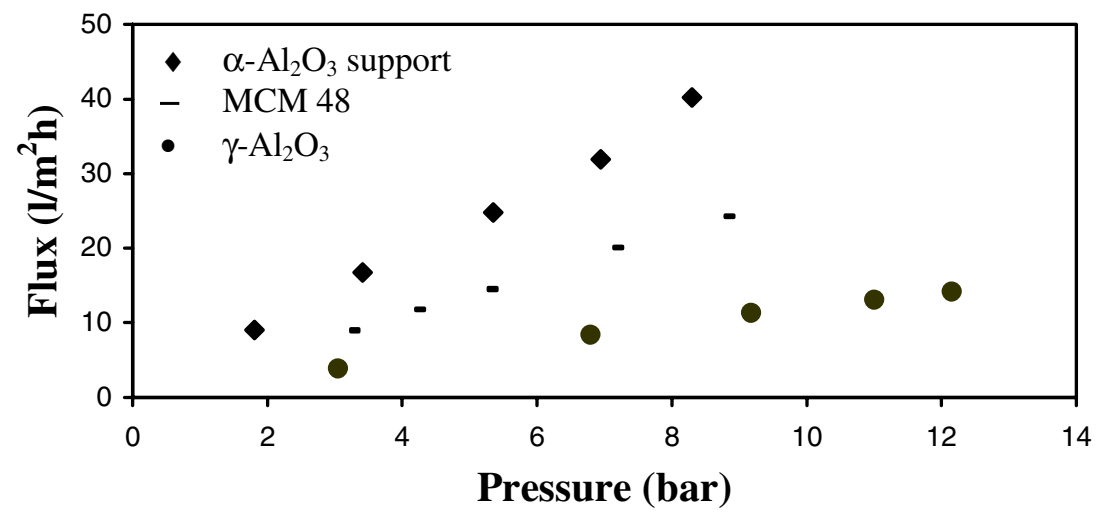

Figure 4. Comparison of water fluxes through $\alpha$-alumina supported MCM-48 and supported $\gamma$ alumina. 
In figure 5 the retention of phenylalanine through MCM-48 is shown. The phenylalanine retention is $20-25 \%$. The $\mathrm{pH}$ of the solution was 4.3 , which is below the isoelectric point of phenylalanine of 5.48. At this $\mathrm{pH}$ the silica surface is negatively charged, but since the solute molecules are positively charged an attractive interaction occurs between the membrane pore surface and the solute molecules. This may explain the relatively low retention of phenylalanine.

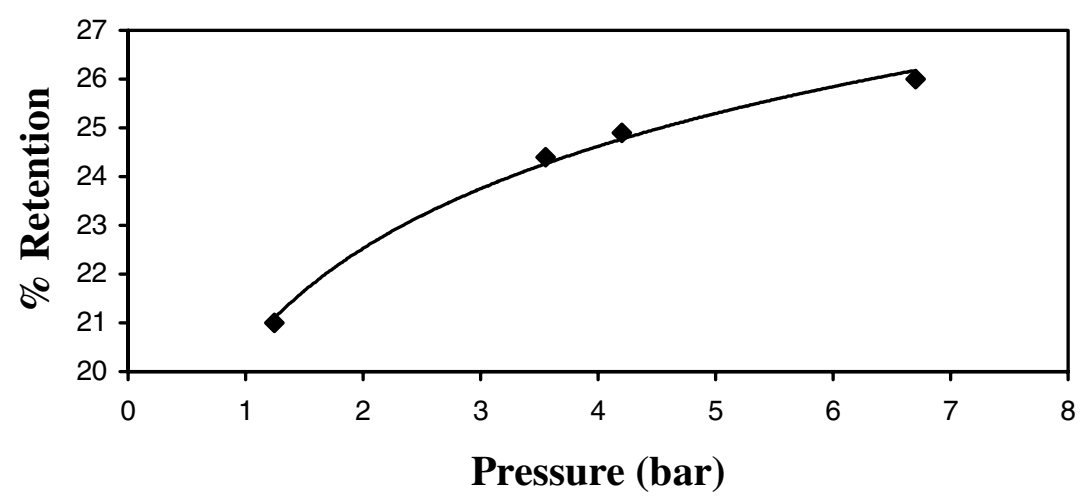

Figure 5. Retention behaviour of phenylalanine in water through MCM-48.

\section{Field mediated transport experiments}

Figure 6 shows the flux of $\mathrm{Cu}^{2+}$ ions versus potential difference $(\Delta V)$. The flux of $\mathrm{Cu}^{2+}$ increased with increasing $\Delta V$. As shown in figure $6 \mathrm{a} \mathrm{Cu}^{2+}$ flux was present at all $\Delta V$ and the flux was directed from the negative to the positive electrode. When $\Delta V=0$, a flux of $\mathrm{Cu}^{2+}$ ions $\left(1.67 \cdot 10^{-4} \mathrm{~mol} \mathrm{~m}^{-2} \mathrm{~s}^{-1}\right)$ was observed. The mode of transport at $\Delta V=0$ is normal Fick diffusion. When $\Delta V>0$ the flux of $\mathrm{Cu}^{2+}$ ions increased, while the flux of $\mathrm{Cu}^{2+}$ ions decreased when $\Delta V<0$. This implies that the transport rate of cations can be controlled over a wide range by external variation of $\Delta V$.

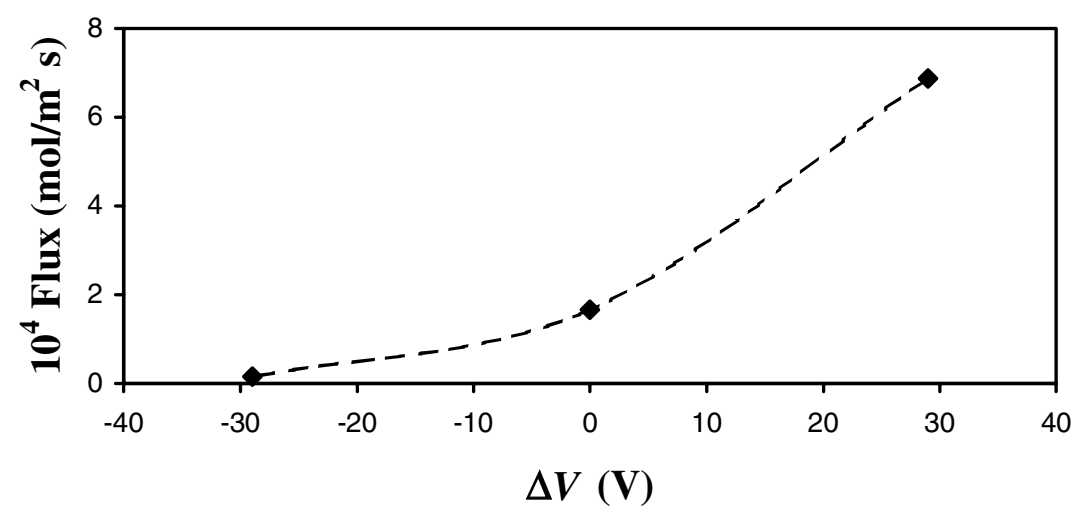

Figure 6. Cationic flux versus $\Delta V$ at low ionic strength. Permeating ion: $\left[\mathrm{CuCl}_{2}\right]=2.3 \mathrm{mM}(\mathrm{A}-$ side), $[\mathrm{KF}]=0.25 \mathrm{mM}$ and $[\mathrm{KCl}]=1.5 \mathrm{mM}$ (B-side); $\mathrm{pH}$ 5.5. Drawn line serves as guide to the eye. 


\section{CONCLUSIONS}

Defect-free MCM-48 layers were deposited on macroporous $\alpha$-alumina supports and silicon microsieves. The alumina-supported MCM-48 membranes showed higher water permeability than conventional $\gamma$-alumina supported membranes. MCM-48 can be applied as NF membrane, as was illustrated by the retention of phenylalanine in water. The application of MCM-48 membranes as ion-selective membrane in electric-field driven ion transport was also demonstrated. It was shown that the cation flux through the microsieve-supported MCM-48 membrane could be controlled by manipulation of the dc potential difference over the membrane.

\section{ACKNOWLEDGMENTS}

Aquamarijn is gratefully acknowledged for providing silicon microsieves. Financial support of the Netherlands Technology Foundation (NWO-STW) and the Commission of the EC in the framework of the Growth Programme, contract no. G1RD-2000-00347 (SUSTOX) is gratefully acknowledged.

\section{REFERENCES}

1. J.S. Beck, J.C. Vartuli, W.J. Roth, M.E. Leonowicz, C.T. Kresge, K.D. Schmitt, C.T.-W. Chu, D.H. Olson, E.W. Sheppard, S.B. McCullen, J.B. Higgins and J.L. Schlenkert, J. Am. Chem. Soc. 114, 10834 (1992).

2. D. Zhao, P. Yang, D.I. Margolese, B.F. Chmelka and G.D. Stucky, Chem. Commun. 2499 (1998).

3. D. Zhao, P. Yang, N. Melosh, J. Feng, B.F. Chmelka and G.D. Stucky, Adv. Mater. 10, 1380 (1998).

4. H. Yang, N. Coombs, I. Sokolov and G.A. Ozin, J. Mater. Chem. 7, 1285 (1997).

5. M. Klotz, A. Ayral, C. Guizard and L. Cot, Sep. Purif. Tech. 25, 71 (2001).

6. M.W. Anderson, Simplified description of MCM-48, Zeolites 19, 220 (1997).

7. P.M. Biesheuvel and W.B.S. de Lint, J. Colloid Interf. Sci. 241, 422 (2001).

8. Micro Total Analysis Systems 2000, ed. A. van den Berg, W. Olthuis and P. Bergveld, (Kluwer, 2000).

9. P.J. Kemery, J.K. Steehler and P.W. Bohn, Langmuir 14, 2884 (1998).

10. T.-C. Kuo, L.A. Sloan, J.V. Sweedler and P.W. Bohn, Langmuir 17, 6298 (2001).

11. M. Nishizawa, V.P. Menon and C.R. Martin, Science 268, 700 (1995).

12. N. Benes, A. Nijmeijer and H. Verweij, "Mesoporous silica membranes", in: N.K. Kanellopoulos (Ed.), Recent advances in gas separation by microporous ceramic membranes, (Elsevier Amsterdam, 2000.) pp.335-372.

13. Honma, H.S. Zhou, D. Kundu and A. Endo, Adv. Mater. 12, 1529 (2000).

14. S. Roy Chowdhury, J.E. ten Elshof, N.E. Benes and K. Keizer, Desalination 144, 41 (2002). 